\title{
Pediatric heart failure
}

\author{
Iolanda Muntean ${ }^{1,2}$, Asmaa Carla Barmou², Liliana Gozar ${ }^{1,2}$, Amalia Fagarasan $^{1,2}$ \\ 1"George Emil Palade" University of Medicine, Pharmacy, Science and Technology, Tg. Mures, Romania \\ ${ }^{2}$ Clinic of Pediatric Cardiology, Emergency Institute of Cardiovascular Diseases and Transplantation, \\ Tg. Mures, Romania
}

ABSTRACT
Pediatric heart failure is a significant challenge in clinical practice, a global burden worldwide. Compared to adult
population, heart failure in children has a variety of etiologies depending on the patients age. However, pediatric
heart failure guidelines are still extrapolated from adult population. In infants and children, the pharmacological
treatment is based on angiotensin-converting enzyme inhibitors, beta-blockers, aldosterone receptors antagonists,
and other diuretics in the presence of congestion, with a lower use of device therapy. In end-stage heart failure, as
a bridge to transplantation or recovery, ventricular assist devices or different palliative surgical interventions are
used nowadays.
This review focuses on the most important causes, pathophysiological mechanisms, clinical manifestation and
management of pediatric heart faliure based on recent guidelines. Furthermore, it emphasize the newer pharmaco-
logical or non-pharmacological therapies that have been recently approved in pediatric population.
Keywords: pediatric heart failure, clinical management, pharmacological treatament, mechanical assist devices, heart transplant

\section{INTRODUCTION}

Pediatric heart failure (HF) is a significant healthcare problem worldwide due to high costs regarding prolong and frequent hospitalization with worse outcomes [1]. Due to lack randomized studies, true prevalence of pediatric HF it is still unknown [2,3]. Pediatric HF guidelines are mostly based on adult guidelines and consensus opinions, making pediatric HF management a significant challenge in clinical practice $[4,5]$. Therefore, this review summarizes the most important issues regarding etiology, classification and HF management in pediatric population.

\section{DEFINITION AND ETIOLOGIES}

According to International Society of Heart and Lung Transplant (ISHLT) guidelines, HF is a "clinical and pathophysiological syndrome that results from ventricular dysfunction, volume or pressure overload, either alone or in combination" [4]. Therefore, the etiology of pediatric HF is divided in two large groups: on one hand, cardiomyopathies (CMP) lead to ventricular dysfunction in patients with structurally normal hearts and on the other hand, congenital heart diseases (CHD) that lead to volume or/and pressure overload [6]. Furthermore, the etiology of HF is different between different age groups. In older patients the most important cause of HF is CMP. At the moment of diagnosis, the incidence rate of $\mathrm{HF}$ that is different between types of CMP: $70 \%$ of patients with dilated cardiomyopathy will present with HF compared with only $13 \%$ of patients with hypertrophic cardiomyopathy (HCM) [7]. Congenital heart diseases (CHD) are the most important cause of HF in newborns and infants. Despite the fact that in the last years, many infants with CHD are been diagnosed early in life and most of them benefited from corrective or palliative surgery that led to an improvement in survival rate, on long-term survivors develop complications over the years that lead to HF $[8,9]$. Also, the etiology of HF varies among different regions: in developing countries severe anemia secondary to malnutrition or malaria is an important cause of HF in children [10,11]. 


\section{HEART FAILURE STAGING}

A correct management of HF should involve appropriate staging of the disease. There are a number of scales used to characterize HF based on clinical appearance: NYHA (The New York Heart Association) or ROSS HF Classification (Table 1). The utility of NYHA classification is limited regarding infants or younger children under 6 year of age, therefore Ross HF Classification was developed for HF staging in infants and younger children. Both grading systems can be used for a proper HF severity grading, but neither one is describing the onset and disease progression [4]. Therefore, a grading system recommended by American Heart Association (AHA) for HF staging in adults was extrapolated in pediatric HF and recognized by ISHLT [12].

\section{PATHOPHYSIOLOGICAL MECHANISMS}

Due to the fact that, in the last years, the pharmacological treatment in HF was based on the pathogenetic pathways that are involved in HF, their pathophysiological consequences and also the stimulation of endogenous repair mechanism, it is essential to understand the pathophysiological mechanisms that are involved in HF.

Therefore, according to Schrantz et al., cardiac output is determined by: preload (blood flow), afterload (vascular resistance), heart rate, myocardial contractility and also ventricular synchronism and ventricular-ventricular interactions [13]. Therefore, a low cardiac output can be a consequence of one or multiple factors.
As a response to a low cardiac output, a series of neurohormonal mechanisms is activated. First of all, the sympathetic nervous system (SNS) activation leads to high amount of catecholamines that will lead to tachycardia, an increase in myocardial contractility and vasoconstriction. Also, activation of SNS will cause an increase in antidiuretic hormone secretion $(\mathrm{ADH})$ and renal retention of water. Second of all, renin-angiotensin-aldosterone system (RAAS) is activated. Angiotensin II is a vasoconstrictor that contributes to ventricular remodeling and increases volume overload, and Aldosterone contributes to renal sodium and water retention [14]. Therefore, activation of the compensatory neuroendocrine mechanisms can restore cardiac stability for a while. In a chronic state, they become maladaptive and lead to cardiomyocytes apoptosis, cardiac fibrosis, ventricular remodeling and increases HF progression [5].

On the other hand, there are a series of peptides (e.g., Atrial natriuretic peptide ANP, brain natriuretic peptide BNP) with physiological effects such as vasodilatation, stimulation of renal sodium excretion and diuresis that can counteract the negative effects determined by SNS and SRAA. Those peptides are destroyed by an enzyme called neprilysin, with elevated values in chronic HF [6].

\section{PHARMACOLOGICAL TREATMENT IN PEDIATRIC HEART FAILURE}

In clinical practice, pharmacological strategies are based on the modulation of four pathophysiological mechanisms: angiotensin II, catecholamines (norepinephrine), aldosterone and neprilysin.

TABLE 1. NYHA/ROSS/ISHLT classification [4,14]

\begin{tabular}{|l|l|l|l|l|l|}
\hline NYHA & Without HF & I & II & III & IV \\
\hline ROSS & - & No symptoms & $\begin{array}{l}\text { Ordinary physical } \\
\text { activity causes } \\
\text { symptoms }\end{array}$ & $\begin{array}{l}\text { Less than ordinary } \\
\text { physical activity causes } \\
\text { symptoms }\end{array}$ & Symptoms occur at rest \\
Stage & $\begin{array}{l}\text { Patients with high } \\
\text { risk to develop } \\
\text { HF with cardiac } \\
\text { function and cavities } \\
\text { dimension- normal }\end{array}$ & $\begin{array}{l}\text { No symptoms } \\
\text { diaphoresis during } \\
\text { alimentation - in new- } \\
\text { borns/infants. Dyspnea } \\
\text {-in older children } \\
\text { structural anomalies } \\
\text { cardiac function, } \\
\text { but without HF } \\
\text { symptoms }\end{array}$ & $\begin{array}{l}\text { limentation - in new- } \\
\text { borns/infants. } \\
\text { Marked dyspnea - in } \\
\text { older children }\end{array}$ & $\begin{array}{l}\text { Tachypnea, diaphoresis, } \\
\text { retraction at rest }\end{array}$ \\
symptoms of HF & Catients from B stage with prior of current & $\begin{array}{l}\text { D } \\
\text { Patients with end-stage HF } \\
\text { that require continuous } \\
\text { treatment with inotropic } \\
\text { agents or Prostaglandin (in } \\
\text { order to maintain ductus } \\
\text { arteriosus patency), } \\
\text { mechanic ventilatory and/ } \\
\text { or circulatory support, HTx }\end{array}$ \\
\hline
\end{tabular}


In order to block the effects of angiotensin II, angiotensin-converting enzyme inhibitors (ACE) and angiotensin receptor blockers (ARB) are currently used. The most used types of angiotensin-converting enzyme inhibitors are Captopril and Enalapril [15]. Studies are now focusing on a newer generation of tissue ACE inhibitor such as Lisinopril. This tissue ACE inhibitors have some advantages compared to serum ACE inhibitors: first of all, the patient's compliance to treatment is better due to a single administration per day; second, it has effective remodeling properties on vascular and myocardial tissue [16,17]. In patients with CHD and left ventricular dysfunction, ACE inhibitors are recommended only in particular situations (e.g., valvular regurgitations) [4].

Angiotensin receptor blockers (ARB) are recommended by ISHLT guidelines in patients that are unable to tolerate ACE inhibitors. The most used types of ARB are Valsartan and Losartan [4].

Recent studies are focusing on an additional method to block the RAAS system. The pharmacological combination between Sacubitril (a neprilysin inhibitor) and Valsartan (ARB) was recently approved by FDA for the treatment of pediatric HF patients above one year old with symptomatic HF. Sacubitril lowers the serum concentration of Neprilysin, therefore it inhibits the catalyzation of natriuretic peptides (ANP, BNP) and promotes vasodilatation. Valsartan inhibits angiotensin II, therefore preventing vasoconstriction. However, regarding patients below one year old, ongoing studies are performed [16].

In order to block the effects of SNS and catecholamines, beta-blockers are used. A number of studies demonstrated beneficial effects in children with HF [16]. Propranolol was the first beta-blocker drug used in pediatric HF therapy, but Carvedilol is the most prescribed beta-blocker nowadays in pediatric HF. Regarding Carvedilol use in clinical practice, contradictory results have been reported in the current literature. Some small studies have suggested beneficial effects of this drug on HF symptoms and ejection fraction $(\mathrm{EF})$, while a multicenter randomized trial didn't show significant benefit in clinical status of patients after 8 months of treatment $[18,19]$. Currently, due to the cardioprotective effect of beta-2 stimulation (due to beta-2 downregulation demonstrated in patients with DCM and HF), more and more clinicians choose a beta-1 selective blocker, like Bisoprolol $[13,20,21]$. The patient's compliance to treatment is better due to a single administration per day.

In patients with stage $\mathrm{C} \mathrm{HF}$, beta-blockers are associated with ACE inhibitors and aldosterone receptor antagonists [12]. However, the utility in patients with single ventricle physiology has not been proven [22].
Heart rate control is essential in HF treatment in order to maintain a balance between myocardial oxygen demand and consumption, and also to prolong ventricular diastole. [13]. In patients with HF, in order to control heart rate, besides beta-blockers, there are other pharmacological drugs used such as Digoxin or Ivabradine. Digoxin can be used in order to relieve HF symptoms in patients with decreased EF in combination with beta-blockers, ACE inhibitors and aldosterone receptor antagonists [4]. However, it is not recommended in patients with preserved EF. The use of Digoxin decreased significantly due to a narrow therapeutical range and interactions with other drugs [19]. Ivabradine is a selective blocker of the pacemaker current $\mathrm{I}_{\mathrm{f}}$, a pure bradycardic agent with low adverse effects. It was recently approved by the FDA in class II to IV (NYHA/ROSS), symptomatic stable patients older than 6 months [16,23].

In order to block the effects of aldosterone, aldosterone receptor antagonists are being used. Despite the fact that they are considered weaker diuretics, they are used due to their antifibrotic properties [4]. In patients with diastolic HF, the use of aldosterone receptor antagonists is not recommended [4]. The most common drug used is Spironolactone, usually associated with $\mathrm{ACE}$ and beta-blockers in stage C patients [24].

In patients with pulmonary or systemic congestion, in order to control the symptoms and reduce water retention, the first-line of therapy is represented by loop diuretics, and the most prescribed loop diuretic is Furosemide [4,25]. Recent studies focused on a newer diuretic: Tolvaptan, a vasopressin V2 receptor antagonist that can be administrated as an additional diuretic drug in pediatric HF patients. Due to its properties, Tolvaptan improves water congestion by increasing urinary output and normalizes serum sodium concentration in patients with hyponatremia [21].

According to recent guidelines, in patients with NYHA/ROSS stage II, it is reasonable to introduce progressively a triple drug association: beta-blockers - ACE inhibitors -aldosterone receptor antagonists (Bisoprolol-Lisinopril-Spironolactone), with associated diuretic therapy if there are signs of pulmonary or systemic congestion $[4,13,26]$. We emphasize the fact that in pediatric HF, most guidelines recommend the use of different pharmacological treatment based on level of evidence C $[6,20]$.

\section{NON-PHARMACOLOGICAL TREATMENT IN ADVANCED CHRONIC HF}

Patients in stage IV NYHA/ROSS require hospitalization and intravenous inotropes. Refractory cases require advanced treatment. Device therapy and different palliative surgical interventions are more and 
more used as a bridge to transplant or recovery.

Device therapy- In the last years, device therapy is required in more pediatric patients. Pacemaker therapy is recommended in patients with atrio-ventricular block type II/III associated with ventricular disfunction [4]. Implantable cardioverter defibrillator (ICD) therapy is recommended in patients after cardio-respiratory arrest [4]. However, it is associated with a suboptimal performance and $25-40 \%$ of patients reported inappropriate shocks [27]. Resynchronization therapy (CRT) is recommended in patients with NYHA functional class II-IV, left ventricle dysfunction with EF below 35\% and QRS duration above normal values for age associated with left bundle branch (class IIa, level of evidence B) or complete right bundle branch (class IIb, level of evidence C) [4]. There are some studies that described the improvement of EF and NYHA functional class in pediatric patients, with complication rates similar in pediatric and adult patients [28].

\section{Mechanical circulatory support and heart transplantation}

On long term, HTx remains the only therapy of choice for end-stage HF patients refractory to maximal medical treatment. As a bridge to transplantation or recovery, ventricular assist devices (VAD) or different surgical interventions are used [29]. Interagen-

Conflict of interest: none declared

Financial support: none declared

\section{REFERENCES}

1. Nakano SJ, Miyamoto SD, Price JF, Rossano JW, Cabrera AG. Pediatric Heart Failure: An evolving public health concern. J Pediatr. 2020 Mar;218:217-221.

2. Ponikowski P, Voors A, Anker SD, et al.; Authors/Task Force Members; Document Reviewers. 2016 ESC Guidelines for the diagnosis and treatment of acute and chronic heart failure: The Task Force for the diagnosis and treatment of acute and chronic heart failure of the European Society of Cardiology (ESC). Developed with the special contribution of the Heart Failure Association (HFA) of the ESC. Eur J Heart Fail. 2016 Aug;18(8):891-975.

3. Hsu DT, Pearson GD. Heart failure in children: Part I: History, etiology and pathophysiology. Circ Heart Fail. 2009 Jan;2(1):63-70.

4. Kirk R, Dipchand AL, Rosenthal DN, et al.; The International Society for Heart and Lung Transplantation guidelines for management of pediatric heart failure: Executive summary. J Heart Lung Transpl. 2014 Sep;33(9):888-909.

5. Anderson $\mathrm{R}$ et al. Chronic cardiac failure: physiology and treatment. In: Pediatric cardiology, 3rd edition. Edinburgh: Churchill Livingstone 2009;257-267.

6. Das BB. Current state of pediatric heart failure. Children (Basel). 2018 Jun 28;5(7):88-98.

7. Wilkinson JD, Landy DC, Colan SD, et al. The pediatric cardiomyopathy registry and heart failure: Key results from the first 15 years. Heart Fail Clin. 2010 Oct;6(4):401-413.

8. Nandi D, Rossano JW. Epidemiology and cost of heart failure in children. Cardiol Young. 2015 Dec;25:1460-1468.

9. James N, Smith M. Treatment of heart failure in children. Current Paediatrics. 2005 Dec;15(7):539-548. cy Registry for Mechanically Assisted Circulatory Support (INTERMACS) developed seven clincal profiles in order to have a better selection of patients in advanced stages and their therapies [30]. VADs implantation is recommended in end-stage HF associated with at least one other major organ dysfunction (class I, level of evidence C) [4].

In DCM patients, Schrantz et al. proposed a reversible pulmonary artery banding as an intervention recommended in children $<6$ years old diagnosed with DCM with HF ROSS/NYHA class III/IV, with reduced LV EF and preserved RV function [31]. Pulmonary artery banding showed beneficial effects regarding LV function, size or EF, but the mortality is still unknown and the efficacity is demonstrated only in infants or young children.

\section{CONCLUSIONS}

Pediatric HF is a complex syndrome with multiple etiologies that leads to significant mortality and morbidity. Despite the advancements in technology, pediatric HF is still a challenge in clinical practice. Further studies should concentrate to a personalized pharmacological therapy in pediatric patients based on targeted pathophysiology, molecular processes and the etiology of HF.

10. Masarone D, Valente F, Rubino M, Vastarella R, Gravino R, Rea A, Russo MG, Pacileo G, Limongelli G. Pediatric Heart Failure: A Practical Guide to Diagnosis and Management. Pediatr Neonatol. 2017 Aug;58(4):303-312.

11. Madriagao E, Silberbach M. Heart failure in infants and children. Pediatr Rev. 2010 Jan;31(1):4-12.

12. Stout KK, Broberg CS, Book WM, Cecchin F, Chen JM, Dimopoulos K, Everitt MD, Gatzoulis M, Harris L, et al.; American Heart Association Council on Clinical Cardiology, Council on Functional Genomics and Translational Biology, and Council on Cardiovascular Radiology and Imaging. Chronic Heart Failure in Congenital Heart Disease: A Scientific Statement From the American Heart Association. Circulation. 2016 Feb 23;133(8):770-801.

13. Schrantz D, Voelkel NF. "Nihilism" of chronic heart failure therapy in children and why effective therapy is withheld. Eur J Pediatr. 2016 Apr;175(4):445-455.

14. Knudson JD, Cabrera AG. The Pathophysiology of heart failure in children: The Basics. Curr Cardiol Rev. 2016;12(2):99-103.

15. Diez CC, Khalil F, Schwender H. et al. Pharmacotherapeutic management of paediatric heart failure and ACE-I use patterns: a European survey. BMJ Paediatrics Open. 2019 Jan;3(1):e000365.

16. Stidham J, Feingold B, Almond CS, Burstein DS, Krack P, Price JF, Schumacher KR, Spinner JA, Rosenthal DN, Lorts A, Godown J. Establishing Baseline Metrics of Heart Failure Medication Use in Children: A Collaborative Effort from the ACTION Network. Pediatr Cardiol. 2021 Feb;42(2):315-323.

17. Gisler F, Knirsch W, Harpes P, Bauersfeld U. Effectiveness of angiotensin-converting enzyme inhibitors in pediatric patients with 
mid to severe aortic valve regurgitation. Pediatr Cardiol. 2008 Sep;29(5):906-9.

18. Rusconi P, Gomez-Marin O, Rossique-Gonzalez M, et al. Carvedilol in children with cardiomyopathy: 3-year experience at a single institution. J Heart Lung Transplant. 2004 Jul;23(7):832-838.

19. Shaddy RE, Boucek MM, Hsu D, et al. Carvedilol for children and adolescents with heart failure: A randomized controlled trial. JAMA. 2007 Sep;298(10):1171-1179.

20. Recla S, Schmidt D, Logeswaran T, Esmaeili A, Schranz D. Pediatric heart failure therapy: why $\beta 1$-receptor blocker, tissue ACE-I and mineralocorticoid-receptor-blocker?. Transl Pediatr. 2019 Apr; 8(2):127-132.

21. Li B, Fang D, Qian C, Feng H, Wang Y. The efficacy and safety of Tolvaptan in patients with hyponatremia: a meta-analysis of randomized controlled trials. Clin Drug Investig. 2017 Apr; 37(4):327-342.

22. Garcia AM, Beatty JT, Nakano JS. Heart failure in single right ventricle congenital heart disease: Physiologic and molecular considerations. Am J Physiol Heart Circ Physiol. 2020 Apr;318(4):H497-H965.

23. Bonnet $D$, Berger $F$, Jokinen $E$, et al. Ivabradine in Children With Dilated Cardiomyopathy and Symptomatic Chronic Heart Failure. J Am Coll Cardiol. 2017 Sep;70(10):1262-1272.

24. Rossano JW, Shaddy RE. Heart failure in children: Etiology and treatment. J Pediatr. 2014 Aug;165(2):228-233.

25. Macicek SM, Macias CG, Jefferies JL, et al. Acute heart failure syndromes in the pediatric emergency department. Pediatrics. 2009 Nov;124(5):e898-904.
26. Kantor PF, Lougheed J, Dancea A et al.; Children's Heart Failure Study Group. Presentation, diagnosis and medical management of heart failure in children: Canadian Cardiovascular Society Guidelines. Can J Cardiol. 2013 Dec;29(12):1535-1552.

27. Atallah J, Erickson C, Cecchin F, et al.; Pediatric and Congenital Electrophysiology Society (PACES). Multi-Institutional study of implantable defibrillator lead performance in children and young adults. Results of the pediatric lead extractability and survival evaluation (PLEASE) study. Circulation. 2013 Jun; 127(24):2393-2402.

28. Janousek J, Gebauer RA, Abdul-Khaliq H, et al. Working Group for Cardiac Dysrhythmias and Electrophysiology of the Association for European Paediatric Cardiology. Cardiac resynchronisation therapy in paediatric and congenital heart disease: differential effects in various anatomical and functional substrates. Heart. $2009 \mathrm{Jul}$; 95(14):1165-1171.

29. Dodd DA. Pediatric heart failure and transplantation: Where are we in 2013?. Curr Opin Pediatr. 2013 Oct; 25(5):553-560.

30. Stevenson LW, Pagani F, Young JB. INTERMACS profile of advanced heart failure: the current picture. J Heart Lung Transplant. 2009 Jun; 28(6):535-541.

31. Schrantz D, Recla S, Malcic I, et al. Pulmonary artery banding in dilative cardiomyopathy of young children: review and protocol based on the current knowledge. Transl Pediatr. 2019 Apr; 8(2):151-160. 